\title{
SIMPÓSIO "O RISO: DIFERENTES PERSPECTIVAS" NOTA INTRODUTÓRIA
}

Os três artigos a seguir procedem de comunicações originalmente apresentadas no simpósio "O riso: diferentes perspectivas" ocorrido durante a 48ㅁ Reunião Anual da Sociedade Brasileira para o Progresso da Ciência, que teve lugar no Campus Monte Alegre da Pontifícia Universidade Católica de São Paulo, entre 7 e 12 de julho de 1996.

Esse simpósio foi uma das 19 seções organizadas pela Sociedade Brasileira de História da Ciência para aquela Reunião. Por isso, parte dos trabalhos aqui incluídos traz particularidades próprias da História da Ciência, que hoje assoma a um espaço adequado à reflexão das ciências naturais e humanas. Servindo de interface entre as múltiplas áreas do conhecimento, também é um campo propício à aproximação entre as culturas científica e humanística, nesta virada de milênio separadas por um fosso colossal. Erigir pontes sobre tal abismo integra as tarefas da História da Ciência, que, de mais a mais, busca reconstituir o contexto subjacente às ciências que a humanidade vem há muito arquitetando.

Nos últimos cinco anos, ainda na trilha aberta por Mikhail Bakhtin (1895-1975) com sua tese sobre A cultura popular na Idade Média e no Renascimento: o contexto de François Rabelais (Hucitec/Editora Universidade de Brasília, 1987), vários estudos históricos acerca do riso vieram à luz. Dentre outros, destacam-se: A Cultural History of Humour (Polity Press, 1997), coletânea organizada por Jan Bremmer e Herman Roodenburg; Laughter at the Foot of the Cross (Penguin Books, 1997), de Michael A. Screech; Enter Rabelais, Laughing (Vanderbilt University Press, 1998), de Barbara C. Bowen; "Between Carnival and Lent: The Scientific Revolution at the Margins of Culture" (Configurations, v.6, p.243-267, 1998), de Paula Findlen; e 0 riso e o risível na história do pensamento (J orge 
Zahar/Editora Fundação Getúlio Vargas, 1999), de Verena A lberti. Em outras palavras, o interesse pelo assunto continua intenso. Justifica-se pois plenamente tornar públicos trabalhos a respeito, apesar de remontarem a 1996, inclusive porque, neste ínterim, afora terem sido lançadas no Brasil traduções relevantes, foi inaugurado na PUC-SP o primeiro Programa de Estudos Pós-Graduados em História da Ciência no país.

Cumpre ainda lembrar que, coordenado por Carlos Arthur R. do Nascimento, o simpósio em tela também contou com a participação de Jerusa de Carvalho Pires Ferreira, professora do Programa de Estudos Pós-Graduados em Comunicação e Semiótica da PUC-SP. Intitulado Agruras do riso, seu trabalho seguiu a argumentação desenvolvida por Vladimir Propp (1895-1970) sobre a interdição do riso. Resumidamente falando, procurou observar a presença da fábula $A$ Princesa que não ria no mundo agrário, o que exigiu acompanhar a rearticulação de segmentos rituais a situarem a vida, a morte e o riso em dimensões várias, do cômico ao escatológico.

Por fim, em nome dos demais integrantes do simpósio "O riso: diferentes perspectivas", resta convidar os leitores de TRANS/FORM/AÇÃO a conhecer alguns meandros históricos ocasionados pela faculdade humana de rir.

Vera Cecília Machline 